\title{
Opportunities for Higher Education of Artificial Intelligence in Korea
}

\author{
Ki-Seok Choi \\ Full Professor, Department of Industrial and Management Engineering, Hankuk University of Foreign Studies, Korea. \\ ORCID: 0000-0003-3885-475X
}

\begin{abstract}
In the recent years, the business environments in Korea, as in most other industrialized countries, have been going under revolutionary changes by adopting artificial intelligence (AI) technology. Since the technology gets popular widely in a short period, there are surging demands of AI manpower not only in the experienced level but also in the entry level. Specifically, we observed by analysing software (SW) job announcements that in about half the cases they require more than 4-year education in college for their new employees without previous job experiences in big data/AI job positions. With the increasing industrial demands in the new technology, there are on-going efforts in higher educational institutes to provide qualified graduates in the AI fields. We surveyed what skills are required in which application fields.
\end{abstract}

Keywords: Higher Education, Artificial Intelligence

\section{INTRODUCTION}

Recently the demand for manpower in the entire SW industry has been steadily increasing in Korea. Among the subclassifications of the SW industry, SW development and supply, computer programming, and system integration and management have the highest demand for manpower and are expected to continue increasing in the future [1]. In particular, the demand for manpower for SW development has played a leading role. Among the SW industry manpower, the proportion of employment according to job types is the highest in application SW developers, system SW developers, and information system operators, in the descending order. The employment share of application software developers is expected to increase in the future along with computer security experts.

The demand for applied SW manpower is highly dependent on the growth of the industries and their requirements on specific technologies. Major industries that are expected to accelerate the increase in the number of employments include information and communications broadcasting, specialized science, health society, and electrical and electronic equipment industries. Those increment are mostly due to the increase in demand for technical manpower resulted from the emergence of new innovative technologies. In addition, other industries, that are expected to decrease the total number of employments due to the revitalization of internet commerce and the emergence of innovative technologies and unmanned services, are wholesale and retail, food and lodging, public administration, and construction industries.

In this paper, we studied the impact of the recent development in AI technologies on the SW industry job markets. Due to the relative complexity of its theoretical backgrounds, AI field needs qualifications different from traditional SW jobs. By analysing the job announcements, we identified the requirements on education level and technical skills, specially for new college graduates who pursue their career in the AIrelated SW industry. We discussed how these changes caused by AI developments can work as the opportunities for higher education institutes in Korea.

\section{SW JOB DEMANDS}

We analysed the number of SW job postings in the information technology industries registered in a representative job portal in Korea, to understand the recent demand for SW manpower in Korea. The number of recruitment announcements is the most for application programmers, web programmers, network/server/security programmers, system programmers, in the order descending order. The survey shows the overall demand for application SW jobs is high.

The portal classifies job postings in the big data/AI field into a separate group. Recruitment announcements for the big data/AI group are the fewest among the SW-related job groups as of the survey. The proportion of big data/AI job postings for employees with no career was $33.3 \%$, which is higher than $25.5 \%$, the average for all job groups. It was significantly higher than $24.1 \%$ for application programmer group and $21.7 \%$ for web programmer group. With the recent expansion of the application of big data/AI technology and the need for it, it is recognized that it is relatively not easy to hire employees with careers. This can be a relatively beneficial effect for job seekers for the first time in their job career, such as those who have just completed their higher education.

The most level of education required for new recruits was a two- or three-year college graduation (including non-academic background and high school graduation). Figure 1 shows that the proportion was $78.5 \%$. In most job groups, the proportion of recruitments requiring a 4-year university graduation or higher is around 19 26\%. However, in the big data/AI job group, $48.7 \%$ of the recruitments of employees with no career

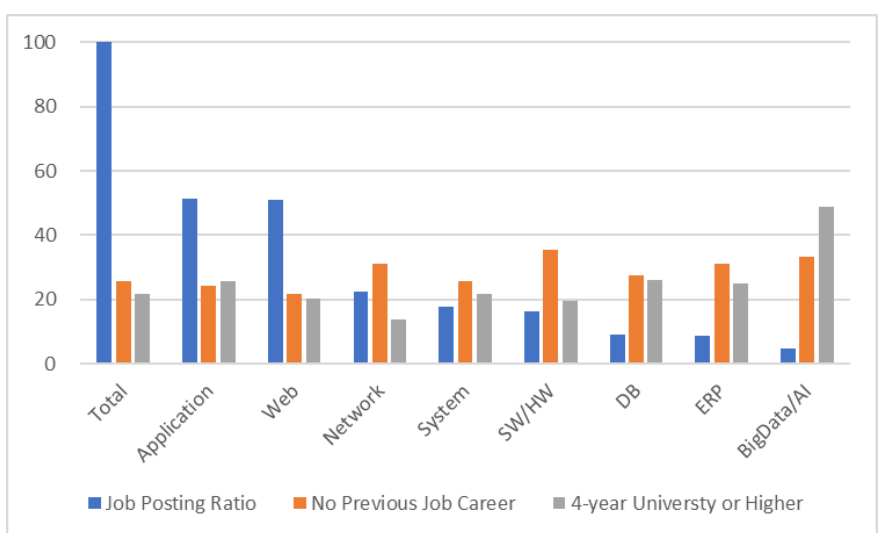

Fig. 1. SW Job Announcement Analysis by Sectors 
required an education level of at least four-year university graduation. It is judged that there are many needs for university graduates in big data/AI jobs. If a higher education institute considers opening a new course in big data/AI, they can meet the industrial needs.

When the companies that want to hire new SW manpower are classified by industry sectors, as expected, IT/information and communication companies accounted for the majority. Other than IT/information communication sector, there were many new recruits of SW manpower in manufacturing production/ chemical sector, and not many in other industry sectors such as service, medical/pharmaceutical, and finance/banking. Recruitment announcements for new SW personnel in department stores/distribution/ wholesale/retail and logistics/ transport/delivery sectors were at the lowest level (Figure 2). Even though IT/information and communication sector hired the most of the new SW employees, only $18.8 \%$ hired new employees with a four-year college degree or higher, which was less than half compared to those employed in other sectors excluding service sector. In comparison, $46.3 \%$ of medical/ pharmaceutical companies and $37.7 \%$ of manufacturing/ production/chemical companies employed new positions with highly educated SW personnel. In the case of logistics/ transportation/delivery and department stores/distribution/ wholesale/retail companies, the ratio of hiring high-educated new recruits was $40.0 \%$ and $33.3 \%$, respectively, but the number of employments in those two sectors were relatively small. In terms of the demand of high-tech graduates, there is an advantage of educating SW manpower specialized in the medical/pharmaceutical and manufacturing/production/ chemical industry sectors. They have a large number of new recruits for SW manpower and a high rate of recruiting new employees with college graduates or higher.

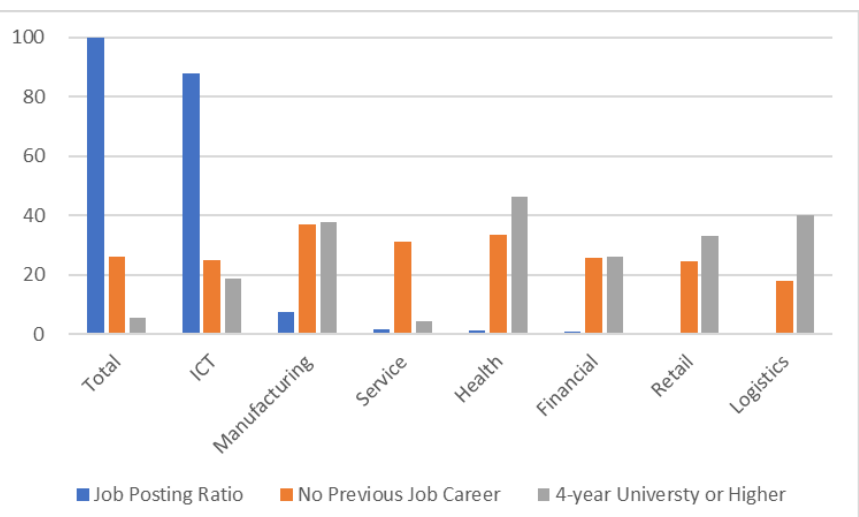

Fig. 2. SW Job Announcement Analysis by Industries

In the field of AI, the related market has been steadily growing around the world. The related market size in the Korea is expected to exceed 11 trillion won in 2020 [2]. According to a survey conducted by Seagate Technology [3], 92\% of the surveyed companies answered that they needed to adopt AI technology to secure competitiveness. The survey showed that $60 \%$ of the companies have already introduced AI technology into their products or services, and $81 \%$ said that they would implement AI-related plans within the next 12 months.

Manpower demand in AI fields is on the rise due to the expansion and development of related industries, but the supply of related manpower is insufficient. According to the previous survey by Seagate Technology, $91 \%$ of the surveyed companies were having difficulty finding employees suitable for adopting artificial intelligence technology. As artificial intelligence manpower is expected to be in short, a national-level manpower training policy has been implemented in Korea. According the policy, 6 AI graduate schools has been established by 2022 [4]. The shortage of AI manpower is the same for practical beginner/intermediate manpower as well as advanced master and doctoral level manpower. Government departments such as the Ministry of Science and Information \& Communication Technology are promoting projects to cultivate working-level workforces for prospective college graduates.

\section{TECHNOLOGY SKILL DEMANDS}

Most of the existing AI education programs focus on teaching the AI frameworks widely used in the industry to develop new services with basic knowledge of deep learning technology. When a higher education institute educates their students in the AI field, it should take into account the curriculum period and the diversity of trainee's major in the previous institute, if any, they enrolled. Of course, the education course also needs to consider the knowledge level and scopes expected by the potential employers. In consideration of the work capabilities of new college graduates required by companies, the basic skills of not only AI technology but also general-purpose programming and data analysis skills in the IT field should be prepared.

In order to find out the abilities that AI related companies require from their new employees, we analysed the hiring announcements for AI SW fields (Table 1). Tensorflow is the most demanded for the ability to use AI platform. Others include Keras, Caffe, PyTorch, etc. As for programming languages, Python is the most in demand. But $\mathrm{C} / \mathrm{C}++$ is also highly required in the application SW development jobs. In addition, through interviews with experts in the AI industry, we confirmed the importance of programming and collaboration skills, which are basic practical skills as a SW developer.

\section{AI-RELATED JOBS AND PREFERRED SKILLS}

According to the statistics from the Venture Business Association, more than half of the 15,782 venture companies are located in metropolitan areas such as Gyeonggi (28.7\%) and Seoul (28.0\%) [5]. According to the Artificial Intelligence Industry Association, which is a group of representative AI companies, AI technology-based SW development and solution companies are also concentrated near Teheran-ro in Gangnam/Seocho-gu, Seoul and Seongnam, Gyeonggi, where Pankyo Techno Valley is located [6]. It is judged that it will be advantageous to provide AI-related education courses on campuses close to the areas where these companies are concentrated in terms of the connection to the industrial demands.

According to the employment portal Job Korea 2016 survey [7], the wage level of new employees varies greatly depending on the size of the company (the initial wage for companies with less than 50 employees is 23.97 million won, which is $66 \%$ of 
International Journal of Engineering Research and Technology. ISSN 0974-3154, Volume 13, Number 11 (2020), pp. $3428-3430$

(C) International Research Publication House. https://dx.doi.org/10.37624/IJERT/13.11.2020.3428-3430

Table 1. Preferred Skills in AI-Related Jobs

\begin{tabular}{|c|c|c|c|c|c|}
\hline \multirow[b]{2}{*}{ No } & \multirow[b]{2}{*}{ Industry } & \multirow[b]{2}{*}{ Job Tasks } & \multicolumn{3}{|c|}{ Preferred Skills } \\
\hline & & & AI Platform & $\begin{array}{c}\text { Programming } \\
\text { Language }\end{array}$ & Etc. \\
\hline 1 & Security & Image Processing & $\begin{array}{l}\text { Tensorflow, Caffe, } \\
\text { Keras }\end{array}$ & $\begin{array}{l}\text { Python, } \mathrm{C} / \mathrm{C}++, \mathrm{C} \# \text {, } \\
\text { Java }\end{array}$ & OpenCV, OpenGL, Vtk, ttk \\
\hline 2 & \multirow{2}{*}{ Finance } & Robot-Advisor & Tensorflow & Python, $\mathrm{C} / \mathrm{C}++, \mathrm{MFC}$ & \\
\hline 3 & & Image Processing & Tensorflow, Keras & Python, Java, C++ & Web/App Development \\
\hline 4 & \multirow{4}{*}{ Health Care } & Image Processing & Tensorflow & Python, $\mathrm{C}++$ & App Development \\
\hline 5 & & Image Processing & $\begin{array}{l}\text { Tensorflow, } \\
\text { PyTorch }\end{array}$ & Python & Data Mining \\
\hline 6 & & Image Processing & & Python, $\mathrm{C}++$, PHP & \\
\hline 7 & & Image Processing & & $\mathrm{C} / \mathrm{C}++$, Matlab & \\
\hline 8 & \multirow{4}{*}{ ICT } & Self-Driving & & $\mathrm{C} / \mathrm{C}++$ & ROS \\
\hline 9 & & Self-Driving & & $\mathrm{C}++$ & OMPL, OpenCV, PCL \\
\hline 10 & & $\begin{array}{l}\text { NLP, } \\
\text { Recommendation }\end{array}$ & & Python, $\mathrm{C}++$ & \\
\hline 11 & & AR & & & AWS, App Development \\
\hline 12 & \multirow{2}{*}{ Manufacturing } & Image Processing & & $\mathrm{C} \#, \mathrm{C}++, \mathrm{MFC}$ & .NET, OpenGL \\
\hline 13 & & Image Processing & & $\mathrm{C} / \mathrm{C}++, \mathrm{MFC}$ & OpenCV, Halcon, Mil \\
\hline
\end{tabular}

the 36.5 million won for companies with 1,000 or more). However, as the position level gets higher, the wage difference by company sizes gets smaller significantly. In the SW industry, companies prefer employees with longer careers. They have a well-established compensation system according to work experiences. Considering these characteristics of job market in the SW industry, the fresh graduates from AI education institute can expect significant salary increases after 3 to 5 years of work experience even in a small-sized company. Also, then, they can have more chances to move to a position with preferred working environments. The career development plans based on those SW industry circumstances make the AI education courses more attractive to potential students.

\section{CONCLUSION}

These days many companies try to enhance their business process and meet the various customer requirements by introducing AI technologies. In the emerging periods of such technologies, the needs for manpower in the related fields such as big data and AI have been rapidly increasing while the supply of well-qualified employees who have not only proper technical understandings but also several-year experiences is highly limited. There are many tech start-ups in Korea, which provide specialized products for various industries. Most of them cannot afford to hire employees with competitive careers. That is why there are more job opportunities in big data/AI job group for fresh college graduates compared to other SW job groups as showed Section 2. It is expected that the industrial demands for AI-related fields keep increasing for now. The new environment evoked by the AI technology is providing an opportunity for the college students but also the higher education institutes in Korea which plan to competitive education to their students.

\section{ACKNOWLEDGEMENTS}

This work was supported by Hankuk University of Foreign Studies Research Fund.

\section{REFERENCES}

[1] Choi MI, Choi JW, Kim JM, Jeon IS. 2020 Software Industry Outlook. Software Policy and Research Institute. 2020.

[2] Korea Internet and Security Agency. 2017 Internet 10 Issues Outlook. 2017.

[3] Seagate, Data Pulse: Maximising the Potential of Artificial Intelligence. 2018.

[4] Ministry of Science and ICT, Artificial Intelligence R\&D Strategy to Realize I-Korea 4.0. 2018

[5] Korea Venture Business Association, Member Companies Statistical Graph. 2020.

[6] Artificial Intelligence Industry Association, Member Companies Status, 2020.

[7] Job Korea, 2016 Annual Salary of New College Graduates. 2016. 